REGARDS

SUR L'ECONOMIE ALLEMANDE

BULLETIN ECONOMIQUE DU CIRAC
Regards sur l'économie allemande

Bulletin économique du CIRAC

$80 \mid 2007$

Varia

\title{
UE : cultures et valeurs
}

HÖLSCHER Michael, Wirtschaftskulturen in der erweiterten EU. Die Einstellungen der Bürgerinnen und Bürger im europäischen Vergleich / REYNIÉ Dominique (dir.), L'opinion européenne en 2007

\section{(2) OpenEdition}

12 Journals

Édition électronique

URL : http://journals.openedition.org/rea/457

DOI : $10.4000 /$ rea. 457

ISBN : 978-2-8218-0856-0

ISSN : 1965-0787

Éditeur

CIRAC

Édition imprimée

Date de publication : 1 mars 2007

ISSN : 1156-8992

Référence électronique

«UE : cultures et valeurs », Regards sur l'économie allemande [En ligne], 80 | mars 2007, document 9 ,

mis en ligne le 23 avril 2008, consulté le 21 septembre 2020. URL : http://journals.openedition.org/rea/ 457 ; DOl : https://doi.org/10.4000/rea.457

Ce document a été généré automatiquement le 21 septembre 2020.

(c) CIRAC 


\section{UE : cultures et valeurs}

HÖLSCHER Michael, Wirtschaftskulturen in der erweiterten EU. Die Einstellungen der Bürgerinnen und Bürger im europäischen Vergleich / REYNIÉ Dominique (dir.), L'opinion européenne en 2007 


\section{RÉFÉRENCE}

HÖLSCHER Michael, Wirtschaftskulturen in der erweiterten EU. Die Einstellungen

der Bürgerinnen und Bürger im europäischen Vergleich, VS Verlag für

Sozialwissenschaften, Wiesbaden, 2006, 285 p.

REYNIÉ Dominique (dir.), L'opinion européenne en 2007, Editions de la Table

Ronde / Fondation Robert Schuman, Paris 2007, 284 p.

1 L'Europe est une réalité «entrée dans les mours, dans la vie quotidienne et dans l'espace de pensée des Européens». Ce qui fait sa richesse, c'est la grande diversité des cultures et systèmes, autrement dit: des identités nationales qui fondent l'unité de l'Europe. En nous présentant les approches diverses de ces thèmes qui préoccupent les Européens (avenir des retraites, santé, salaires), de même que leurs valeurs et comportements (des pratiques religieuses au football en passant par le cinéma), cette $7^{\mathrm{e}}$ édition de «L'opinion européenne » nous plonge dans la réalité vécue et vivante de l'Europe. Dans le même ordre d'esprit, mais suivant une approche empirique de psychologie de l'économie, M. Hölscher se penche sur les différences et similitudes constatées dans les cultures économiques des Etats membres. Il identifie trois grandes familles de cultures, qui séparent les anciens et nouveaux membres (de même que les candidats à l'adhésion). La première est peu ouverte au monde et peu axée sur la performance : elle comprend tous les 'vieux' Etats membres, sauf les Pays Bas. La seconde (pays scandinaves et Pays Bas) se caractérise par un grand degré d'ouverture. La troisième, par la priorité accordée à la performance, largement entretenue par le processus de rattrapage : on y trouve les Etats membres est-européens et le Portugal. Ces disparités devraient être plus largement prises en compte dans la définition du «modèle » européen, en conclut l'auteur. (ib) 